\title{
Dietary habits and physical activity levels in Jordanian adolescents attending private versus public schools
}

\author{
R.F. Tayyem, ${ }^{7}$ H.M. Al-Hazzaa, ${ }^{2}$ S.S. Abu-Mweis, ${ }^{1}$ H.A. Bawadi, ${ }^{3}$ S.S. Hammad and A.O. Musaiger $^{4}$
}

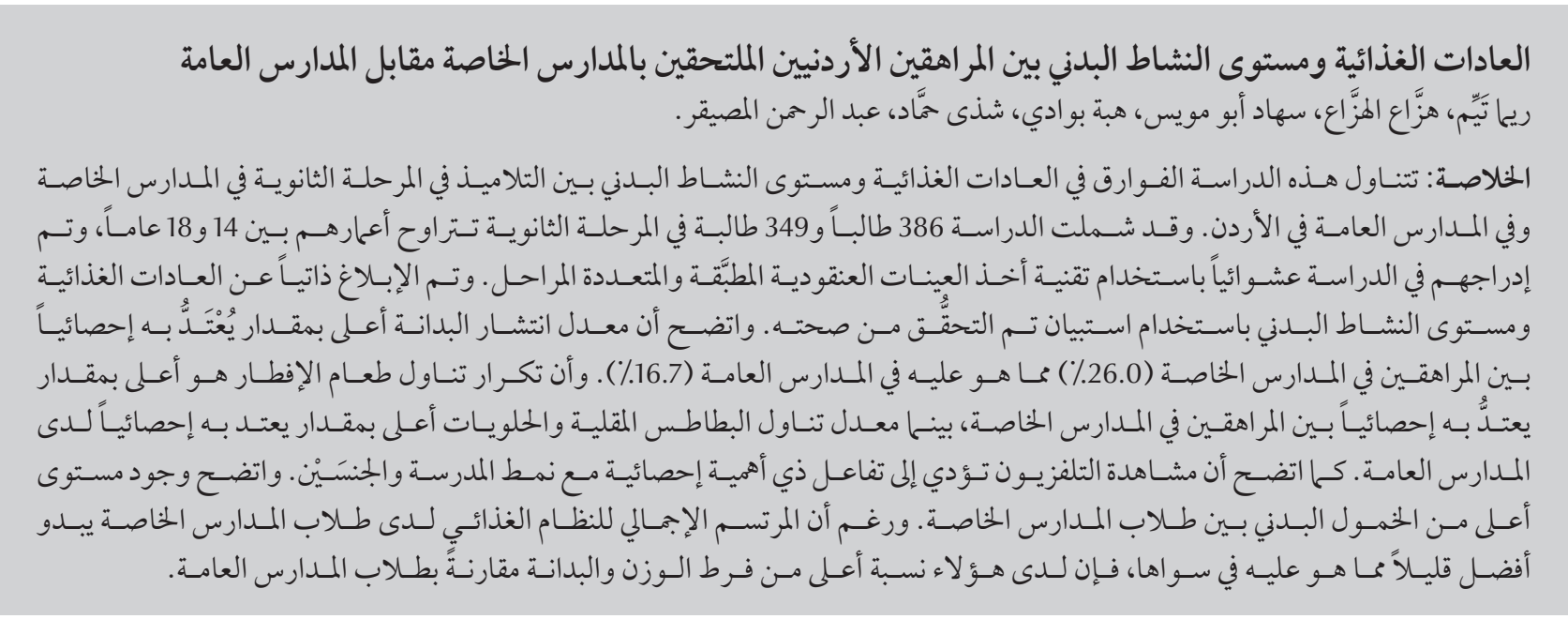

ABSTRACT The present study examined differences in dietary habits and physical activity levels between students attending private and public high schools in Jordan. A total of 386 secondary-school males and 349 females aged 14-18 years were randomly recruited using a multistage, stratified, cluster sampling technique. Dietary habits and physical activity level were self-reported in a validated questionnaire. The prevalence of obesity was significantly higher among adolescents in private (26.0\%) than in public schools (16.7\%). The frequency of breakfast intake was significantly higher among adolescents in private schools, whereas French fries and sweets intake was significantly higher in public schools. Television viewing showed a significant interaction with school type by sex. A higher rate of inactivity was found among students attending private schools. Despite a slightly better overall dietary profile for students in private schools, they had a higher rate of overweight and obesity compared with those in public schools.

\section{Habitudes alimentaires et niveau d'activité physique chez les adolescents jordaniens fréquentant une école privée par rapport à ceux fréquentant une école publique}

RÉSUMÉ La présente étude a examiné les différences dans les habitudes alimentaires et les niveaux d'activité physique entre les élèves des écoles publiques et ceux des écoles privées en Jordanie. Au total, 386 garçons et 349 filles fréquentant des établissements d'enseignement secondaires âgés de 14 à 18 ans ont été recrutés aléatoirement au moyen d'une technique d'échantillonnage en grappes, stratifié à plusieurs degrés. Les habitudes alimentaires et le niveau d'activité physique ont été autodéclarés à l'aide d'un questionnaire validé. La prévalence de l'obésité était significativement plus élevée chez les adolescents des écoles privées (26,0 \%) que chez ceux des écoles publiques (16,7\%). La prise d'un petit-déjeuner était nettement plus fréquente chez les adolescents des écoles privées, tandis que la consommation de frites et de sucreries était beaucoup plus importante chez les élèves des écoles publiques. Le nombre d'heures passées à regarder la télévision était très différent entre les élèves des écoles privées et ceux des écoles publiques en fonction du sexe. Un taux d'inactivité plus élevé a été observé chez les élèves des écoles privées. En dépit du profil diététique légèrement meilleur des élèves des écoles privées, leurs taux de surpoids et d'obésité étaient supérieurs à ceux des écoles publiques.

'Department of Clinical Nutrition and Dietetics, The Hashemite University, Zarqa, Jordan (Correspondence to R.F.Tayyem: rtayyem@hu.edu.jo). ${ }^{2}$ Pediatric Exercise Physiology Research Laboratory, College of Education, King Saud University, Riyadh, Saudi Arabia. ${ }^{3}$ Department of Nutrition and Food Technology, Jordan University of Science and Technology, Irbid, Jordan. ${ }^{4}$ Arab Center for Nutrition, Manama, Bahrain, and Nutrition and Health Studies Unit, Deanship of Scientific Research, University of Bahrain, Sakheer, Bahrain.

Received: 11/07/13; accepted: 04/02/14 


\section{Introduction}

Studies in Arab countries have shown a high prevalence of overweight and obesity among adolescents, with rates ranging from $25 \%$ to $60 \%$ (1). The prevalence of overweight among Jordanian male and female adolescents was found to be $21.6 \%$ and $17.5 \%$ respectively (2). Poor eating habits and physical inactivity are the most important risk factors for obesity and other chronic diseases (3). Dietary and lifestyle behaviours of adolescents in the Middle Eastern countries have changed dramatically during the past 2 decades (1). Studies in several Arab countries have shown that the food habits of adolescents are characterized by high intakes of food rich in fat and calories, as well as in salt and sugar. In Saudi Arabia for example, Al-Hazzaa et al. found that about twothirds of Saudi adolescents consumed sugar-sweetened drinks more than 3 times a week, and about a third of them consumed fast food more than 3 times a week (4). In Bahrain, half of the adolescents do not eat breakfast daily, and about third of them rarely ate fruits and/ or vegetables (5). Furthermore, inactivity and a sedentary lifestyle have become widespread among adolescents in this region. For example, about -third of Bahraini adolescents watched television for more than 5 hours a day, and about $69 \%$ of males practised sports everyday compared with $31 \%$ of females (5).

Few studies have correlated obesity, dietary habits and lifestyles of children and adolescents with socioeconomic status (SES) in developing countries (6-8). Although not the most commonly used indicator, school type (private versus public) can be a proxy for SES because the majority of students enrolled in private schools come from moderate- to high-income families $(6,7)$. The prevalence of unhealthy weight, undesirable dietary patterns, sedentary behaviours and physical inactivity has been found to be markedly higher in private than public schools in many countries. A study by Chakar and Salameh showed that the prevalence of obesity and overweight was $7.5 \%$ and 24.4\% respectively among Lebanese adolescent attending private schools (6). They attributed this to the higher SES of pupils at private schools, which could allow a greater adoption of unhealthy nutritional habits (fast food, energy-dense snacks, sweets, etc.) (6). In Sana'a city, Yemen, overweight and obesity had a significantly higher prevalence among children attending private schools (7). Another study, in Pakistan, found that the prevalence of overweight (including obesity) was significantly higher among private schoolboys (9). However, Al-Nuaim et al. reported that Saudi female adolescents who attended public schools were more active than those who attended private schools (10).

The aim of this study was to investigate the differences in anthropometric measurements, dietary habits and lifestyle factors between students attending private and public schools in Jordan. To the researchers' knowledge this is the first study of its kind in Jordan.

\section{Methods}

\section{Sample}

The present study is part of the Arab Teens Lifestyle Study (ATLS), which is a pan-Arab, school-based, multicentre collaborative project conducted between October and December of 2009 (11). The study protocol and procedures were approved by the ethics committee of the Jordanian Ministry of Education.

The participants were adolescent males and females selected from grades 10, 11 and 12 of 8 secondary schools in the capital of Jordan, Amman. The minimum sample size was determined so that the sample proportion would be within \pm 0.05 of the population proportion with a $95 \%$ confidence level. The population proportion was assumed to be 0.50 , as this magnitude yield the maximum possible sample size required.

To gather the required sample, a multistage, stratified, cluster random sampling technique was used. In the first stage, a systematic, random sampling procedure was used to select the schools. The schools were stratified into boys' and girls' secondary schools, with further stratification into public and private schools. Four large public schools as well as 4 private schools were selected. Girls and boys were selected from 2 private and 2 public schools. The selection of private and public schools was proportional to population size. All students in the selected classes who were free from any physical deformity were invited to participate in the study. A formal letter from the Ministry of Education was directed to the schools to facilitate completing the validated questionnaire. All the schools and students were formally consented to be involved in the survey. The final sample size consisted of 735 adolescents (386 males and 349 females; 353 students from public schools 382 from private schools).

\section{Data collection}

\section{Anthropometric measurements}

Body weight was measured with students wearing minimal clothing and without shoes and to the nearest $100 \mathrm{~g}$ using a calibrated portable scale. Height was measured in the full standing position without shoes and to the nearest $0.1 \mathrm{~cm}$ using a calibrated portable measuring rod. Body mass index (BMI) was calculated as the ratio of weight $(\mathrm{kg})$ to the square of height $(\mathrm{m})$. The International Obesity Task Force ageand sex-specific BMI reference values were used to define overweight and obesity in adolescents aged $14-17$ years (12). For participants aged 18 years, we used the cut-off points for adults (overweight $25-29.9 \mathrm{~kg} / \mathrm{m}^{2}$; obesity $\geq$ $30 \mathrm{~kg} / \mathrm{m}^{2}$ ). Waist circumference (WC) was measured horizontally to the nearest centimetre using a non-stretchable 
measuring tape at the level of the umbilical and after gentle expiration. Waist to height ratio (WHtR) was calculated as the ratio between $\mathrm{WC}$ in $\mathrm{cm}$ and height in $\mathrm{cm}$.

\section{Assessment of lifestyle factors}

Lifestyle factors were assessed by a validated, self-reported questionnaire and included physical activity, sedentary behaviours and dietary habits $(11,13,14)$. The ATLS research instrument was used for the assessment of lifestyle factors. The participants completed the ATLS questionnaire in their classrooms under the supervision of their teachers and the research assistants. The physical activity questionnaire collects self-reported data on the frequency, duration and intensity of light, moderate and vigorous intensity physical activities during a typical (usual) week. The physical activity questionnaire has been shown to have a high reliability and acceptable validity against pedometerassessed activity in females and males aged 14-19 years $(11,15)$.

The physical activity questionnaire covers several domains, including transport, household, fitness and sporting activities. Physical activities were assigned metabolic-equivalent (MET) values based on the compendium of physical activity (16) and the compendium of physical activity for youth (17).
Moderate intensity physical activities include activities with values of 3-6 METs, such as normal pace walking, brisk walking, recreational swimming, household activities and recreational sports such as volleyball, badminton and table tennis. Vigorous intensity physical activities and sports included activities with values $>6 \mathrm{MET}$, such as stair climbing, jogging, running, cycling, self-defence, weight training, soccer, basketball, handball and singles tennis. For physical activity cut-off values, we used 60 minutes of daily moderate-intensity physical activity. The sedentary behaviours included questions related to typical daily time in hours spent viewing television (TV) and/or video, playing computer games or using a computer and the Internet. Total screen time was classified as $>5$ hours per day, 3-4 hours per day and $<2$ hours per day.

Questions dealing with dietary habits included some healthy and unhealthy dietary habits and were related to how many times per week the participant consumed breakfast, vegetables (cooked and uncooked), fruit, milk and dairy products, sugar-sweetened beverages (including soft drinks), doughnuts/cakes, sweets and chocolates, energy drinks and fast foods. The student has a choice of answers, ranging from 0 intake (never) to a maximum intake of 7 days per week (every day).
Dietary habits were categorized into 3 levels of intake: $>5$ days/week, 3-4 days/week and $<3$ days/week.

\section{Data analysis}

The data were analysed using SPSS, version 15. Questionnaires with missing responses were excluded. The data were examined for any clustering effect, but there was no evidence of data clustering in the sample, as intra-class correlation coefficients were very low (averaging 0.016) and were insignificant $(P=0.377)$. Descriptive statistics are presented as means and standard error of the mean (SE) or proportions. Multivariate analysis of covariance (MANCOVA) was also used, while controlling for the effects of age, to test for differences in lifestyle variables across sex (males and females) and school type (public and private). The chi-squared test was used to find the significance between private and public schools in the non-continuous (proportions) parameters. The level of significance was set at $P<0.05$.

\section{Results}

Table 1 shows the demographic characteristics and anthropometric measurements of the students. Adolescents from private schools in the 3 sampled school

\begin{tabular}{|c|c|c|c|}
\hline Variable & $\begin{array}{l}\text { Public schoolchildren } \\
\qquad(n=386)\end{array}$ & $\begin{array}{l}\text { Private schoolchildren } \\
\qquad(n=349)\end{array}$ & $P$-value ${ }^{a}$ \\
\hline Male:female ratio (\%) & 52.9:47.1 & 52.1:47.9 & 0.882 \\
\hline Age (years) [mean (SE)] & $16.6(0.95)$ & $15.8(0.86)$ & 0.001 \\
\hline Body weight (kg) [mean (SE)] & $59.1(0.77)$ & $62.5(0.69)$ & 0.038 \\
\hline Height (cm) [mean (SE)] & $166(0.5)$ & $166(0.4)$ & 0.515 \\
\hline BMI [mean (SE)] & $21.4(0.22)$ & $22.5(0.21)$ & 0.003 \\
\hline Waist circumference (cm) [mean (SE)] & $77.5(0.61)$ & $79.3(0.53)$ & 0.258 \\
\hline Waist/height ratio (\%) [mean (SE)] & $46.8(0.003)$ & $47.7(0.003)$ & 0.160 \\
\hline Overweight or obese (\%) & 16.7 & 26.0 & 0.002 \\
\hline Overweight (\%) & 10.2 & 18.4 & 0.005 \\
\hline Obese (\%) & 6.5 & 7.6 & 0.005 \\
\hline
\end{tabular}


grades were significantly $(P<0.001)$ younger $[15.8$ (SE 0.86) years] than their counterparts from public schools [16.6 (SE 0.95) years]. A significantly higher mean body weight $(P<0.003)$ and BMI $(P<0.038)$ was recorded in students attending private schools. The combined prevalence of obesity and overweight was significantly higher in students from private schools (26.0\%) compared with those in public schools $(16.7 \%)(P<0.005)$.

For the dietary intake study 52 questionnaires from public and 9 from private schools were excluded due to missing answers. Frequency of intake of breakfast, sweets and French fries per week showed a significant difference between the 2 types of schools (Table 2). Frequency of breakfast intake per week was higher among the private schoolstudents, while sweets and French fries intake was higher among public schoolstudents.

The results of dietary habits among studied Jordanian adolescents relative to school type and sex, while controlling for the effect of age, are shown in Table 3. There were significant differences between the sexes by type of school in relation to weekly intakes of fast food and sweets $(P<0.05)$. Boys and girls had significantly different weekly rates of consumption of most of the foods assessed in the study (breakfast, fruits, milk, sugar-sweetened drinks, fast food, sweets French fries, and cake/ doughnuts $)(P<0.05)$. Compared with students in private schools, students in public schools reported significantly higher intakes of sweets and French fries $(P<0.05)$ and lower intake of breakfast $(P<0.05)$.

Table 4 shows the MANCOVA results for sedentary behaviours, sleep duration and physical activity levels among the Jordanian adolescents relative to school type and sex. Only TV viewing showed a significant difference with school type by sex interaction effect $(P<0.05)$. In addition, boys and girls showed significant differences in the reported rates of vigorous intensity and total physical activity, while age had a significant effect on TV viewing, computer use and moderate intensity physical activity $(P<0.05)$.

The proportions of Jordanian adolescents who exceeded certain cut-off values for screen time, physical inactivity and selected dietary habits relative to school type are shown in Table 5. Higher rates of inactivity were found among students attending private schools, whereas adolescents in public schools were significantly more likely to exceed 3 days per week intake of sweets/chocolates and French fries/ potato chips $(P<0.05)$.

\section{Discussion}

The present study found a significant difference in the prevalence of obesity among adolescents in private schools (26.0\%) than those in public ones (16.7\%). The frequency of French fries and sweets intake was significantly higher in public schools. On the other hand, breakfast intake was significantly higher among adolescents in private schools. The other dietary habits, sleep duration and physical activity levels was similar in both school types.

Similar results of the combined prevalence of overweight and obesity in students attending public and private schools had been shown by Raja'a and Bin Mohanna (7). They reported that the prevalence of obesity and overweight was $6.5 \%$ and $23.7 \%$ in Yamani public and private schools respectively. Our findings also agree with the results of another study, conducted on Pakistani schoolchildren, which reported overweight prevalence rates of $24.0 \%$ and $8.7 \%$ in private and public schools respectively (9). Moreover, the

\begin{tabular}{|c|c|c|c|}
\hline \multirow[t]{2}{*}{ Food type } & $\begin{array}{l}\text { Public schoolchildren } \\
\qquad(n=334)\end{array}$ & $\begin{array}{l}\text { Private schoolchildren } \\
\qquad(n=341)\end{array}$ & $P$-value \\
\hline & $\begin{array}{l}\text { Mean (SD) intake } \\
\text { (days/week) }\end{array}$ & $\begin{array}{l}\text { Mean (SD) intake } \\
\text { (days/week) }\end{array}$ & \\
\hline Breakfast & $3.0(0.13)$ & $3.5(0.14)$ & 0.019 \\
\hline Vegetables & $4.3(0.12)$ & $4.6(0.11)$ & 0.137 \\
\hline Fruits & $4.1(0.12)$ & $4.3(0.12)$ & 0.286 \\
\hline Milk & $3.9(0.13)$ & $4.2(0.12)$ & 0.231 \\
\hline Sugar-sweetened drinks & $5.2(0.13)$ & $5.1(0.12)$ & 0.655 \\
\hline Fast foods & $2.3(0.11)$ & $2.4(0.10)$ & 0.253 \\
\hline French fries/potato chips & $4.1(0.13)$ & $3.7(0.13)$ & 0.020 \\
\hline Cake/doughnuts & $3.6(0.13)$ & $3.3(0.13)$ & 0.057 \\
\hline Sweets & $4.6(0.13)$ & $4.1(0.12)$ & 0.002 \\
\hline Energy drinks & $0.9(0.10)$ & $1.1(0.11)$ & 0.321 \\
\hline
\end{tabular}

$S D=$ standard deviation. 


\begin{tabular}{|c|c|c|c|c|}
\hline \multirow[t]{2}{*}{ Food type/sex } & \multicolumn{2}{|c|}{ Public schoolchildren } & \multicolumn{2}{|c|}{ Private schoolchildren } \\
\hline & No. & $\begin{array}{l}\text { Mean (SE) intake } \\
\text { (days/week) }\end{array}$ & No. & $\begin{array}{l}\text { Mean (SE) intake } \\
\text { (days/week) }\end{array}$ \\
\hline \multicolumn{5}{|l|}{ Breakfast $^{b c}$} \\
\hline Males & 174 & $3.7(0.20)$ & 189 & $3.9(0.19)$ \\
\hline Females & 160 & $2.3(0.18)$ & 152 & $3.0(0.18)$ \\
\hline \multicolumn{5}{|l|}{ Vegetables } \\
\hline Males & 174 & $4.4(0.17)$ & 189 & $4.6(0.16)$ \\
\hline Females & 160 & $4.3(0.16)$ & 152 & $4.7(0.15)$ \\
\hline \multicolumn{5}{|l|}{ Fruits $^{c}$} \\
\hline Males & 174 & $4.4(0.18)$ & 189 & $4.5(0.16)$ \\
\hline Females & 160 & $3.9(0.16)$ & 152 & $4.2(0.15)$ \\
\hline \multicolumn{5}{|l|}{ Milkc } \\
\hline Males & 174 & $4.4(0.19)$ & 189 & $4.4(0.18)$ \\
\hline Females & 160 & $3.5(0.20)$ & 152 & $3.7(0.19)$ \\
\hline \multicolumn{5}{|c|}{ Sugar-sweetened drinks ${ }^{c}$} \\
\hline Males & 174 & $5.5(0.17)$ & 189 & $5.4(0.18)$ \\
\hline Females & 160 & $4.8(0.18)$ & 152 & $4.8(0.16)$ \\
\hline \multicolumn{5}{|l|}{ Fast foods ${ }^{c, d}$} \\
\hline Males & 174 & $2.4(0.15)$ & 189 & $2.9(0.15)$ \\
\hline Females & 160 & $2.1(0.14)$ & 152 & $2.0(0.14)$ \\
\hline \multicolumn{5}{|c|}{ French fries/potato chips ${ }^{b, c}$} \\
\hline Males & 174 & $3.8(0.18)$ & 189 & $3.5(0.17)$ \\
\hline Females & 160 & $4.5(0.19)$ & 152 & $4.1(0.18)$ \\
\hline \multicolumn{5}{|c|}{ Cake/doughnuts } \\
\hline Males & 174 & $3.5(0.18)$ & 189 & $3.2(0.18)$ \\
\hline Females & 160 & $3.8(0.19)$ & 152 & $3.6(0.18)$ \\
\hline \multicolumn{5}{|l|}{ Sweets ${ }^{b, c, d}$} \\
\hline Males & 174 & $4.1(0.17)$ & 189 & $4.0(0.19)$ \\
\hline Females & 160 & $5.2(0.16)$ & 152 & $4.3(0.18)$ \\
\hline \multicolumn{5}{|l|}{ Energy drinks } \\
\hline Males & 174 & $1.0(0.15)$ & 189 & $1.2(0.14)$ \\
\hline Females & 160 & $0.8(0.14)$ & 152 & $0.9(0.14)$ \\
\hline
\end{tabular}

Between-subjects effects significant at $P<0.05$ for the effect of: ${ }^{a}$ age, ${ }^{b}$ school type ${ }^{c}$ sex and ${ }^{d}$ school type by sex. $S E=$ standard error

prevalence of combined overweight and obesity was shown to be markedly higher in private schools (boys: 37\%; girls: $33 \%$ ) than in public schools (boys: $33 \%$; girls: 20\%) schools in the Seychelles (18).

The current study revealed that there were significant interactions of sex and school type with the frequencies of fast food and sweets intake. Males but not females in private schools were consuming fast foods more frequently per week than were males in public schools. It has been documented that regular consumption of breakfast provides some protection against weight gain (19). However, in the present study, students from private schools were reporting more frequent intake of breakfast, yet they had a higher percentage of overweight and obesity than students in public schools. This discrepancy can be explained by the fact that not all studies have associated skipping breakfast with overweight (20). In addition, the type of breakfast can also make a difference. A study by Deshmukh-Taskar et al. reported that the prevalence of obesity was higher among children and adolescents skipping breakfast than in those consuming ready-to-eat cereals and it was higher among adolescents eating breakfast other than ready-to-eat cereals (21). In addition, higher BMI in private schools could be attributed to the higher total calorie intake among 


\begin{tabular}{|c|c|c|c|c|}
\hline \multirow[t]{2}{*}{ Activity/sex } & \multicolumn{2}{|c|}{ Public schoolchildren } & \multicolumn{2}{|c|}{ Private schoolchildren } \\
\hline & No. & Mean (SE) & No. & Mean (SE) \\
\hline \multicolumn{5}{|c|}{ Duration of sedentary activities (h/day) } \\
\hline \multicolumn{5}{|c|}{$T V$ viewing $^{a, d}$} \\
\hline Males & 174 & $3.3(0.12)$ & 189 & $3.4(0.12)$ \\
\hline Females & 160 & $3.9(0.14)$ & 152 & $3.3(0.13)$ \\
\hline \multicolumn{5}{|c|}{ Computer use $e^{a}$} \\
\hline Males & 174 & $3.1(0.14)$ & 189 & $3.3(0.13)$ \\
\hline Females & 160 & $3.3(0.15)$ & 152 & $3.1(0.15)$ \\
\hline \multicolumn{5}{|l|}{ Sleeping } \\
\hline Males & 174 & $5.0(0.13)$ & 189 & $5.1(0.14)$ \\
\hline Females & 160 & $5.2(0.13)$ & 152 & $4.9(0.14)$ \\
\hline \multicolumn{5}{|c|}{ Amount of physical activity (METs min/week) } \\
\hline \multicolumn{5}{|c|}{ Moderate intensity ${ }^{a}$} \\
\hline Males & 174 & $1413(76)$ & 189 & $1139(76)$ \\
\hline Females & 160 & $1062(83)$ & 152 & $1080(81)$ \\
\hline \multicolumn{5}{|c|}{ Vigorous intensity ${ }^{c}$} \\
\hline Males & 174 & $3388(177)$ & 189 & $3521(176)$ \\
\hline Females & 160 & 970 (193) & 152 & 987 (188) \\
\hline \multicolumn{5}{|l|}{ Totalc } \\
\hline Males & 174 & 4801 (228) & 189 & $4660(207)$ \\
\hline Females & 160 & 2031 (208) & 152 & $2068(222)$ \\
\hline
\end{tabular}

Between-subjects effects significant at $P<0.05$ for the effect of: ${ }^{a}$ age, ${ }^{b}$ school type ${ }^{c}$ sex and ${ }^{d}$ school type by sex. MET $=$ metabolic-equivalent $; S E=$ standard error.

students in private schools (21). However, in the current study no assessment of total energy intake was done.

Females but not males in the public schools reported more frequent intake of sweets compared with females from private schools. In addition, no significant differences in the frequencies of intake of vegetables, fruit, milk, fast foods, sugar-sweetened and energy drinks were detected between students of private and public schools. However, a higher intake of fast foods, soft drinks, fruit juices, fruit, sweets and chips was demonstrated in students of private schools than in government schools in Qureshi et al.'s study (9). Although no significant difference in sedentary behaviours, sleep duration or physical activity levels were detected relative to school type in the present study, the METs-min/week of total physical activity and vigorous physical activity were found to be higher among male students in public than in private schools (9). The lower level of physical activity in females has generally been acknowledged across different cultures $(6,22,23)$. Even though higher intake of French fries and sweets was reported by students in public schools, the higher intake of fast foods and lower (but not significant) total METs-min/week of activity were found in students attending private schools. This could partially explain the higher prevalence of obesity and overweight among students attending private schools.

Another explanation is the higher SES in students attending private schools. Most of the available studies assessed the association between obesity in children and SES (low or middle income) in developing countries rather than depending on type of school. The validity of using attendance of private school or public school as an indicator of SES may vary from one population to another. Many families of high SES also attend public schools. Furthermore, students in public schools do not occupy a specific SES category but, instead, they represent largely different socioeconomic positions, from highest to lowest, with the majority of them coming from the lowest SES. However, the situation in Jordan is different. In Jordan, attending private or public schools is highly associated with SES $(24,25)$. Also, Qureshi et al. showed that the higher food intake among students attending private schools may be because they receive more pocket money than government schoolboys (9).

\section{Limitations of the study}

A valid and reliable questionnaire was used to obtain collect data from the students. However, the data were 


\begin{tabular}{|c|c|c|c|}
\hline \multirow[t]{2}{*}{ Variable (cut-off) } & \multicolumn{2}{|c|}{$\%$ of children exceeding cut-off } & \multirow[t]{2}{*}{$P$-value } \\
\hline & $\begin{array}{l}\text { Public schoolchildren } \\
\qquad(n=334)\end{array}$ & $\begin{array}{l}\text { Private schoolchildren } \\
\qquad(n=341)\end{array}$ & \\
\hline Screen time $>2 \mathrm{~h} /$ day & 96.0 & 96.6 & 0.548 \\
\hline Physical inactivity (< 60 min/day) & 30.6 & 37.4 & 0.030 \\
\hline Daily breakfast & 21.1 & 26.2 & 0.108 \\
\hline Daily vegetables & 25.3 & 31.2 & 0.447 \\
\hline Daily fruit & 20.7 & 24.4 & 0.523 \\
\hline Daily milk & 25.9 & 30.4 & 0.845 \\
\hline Sugar-sweetened drinks (> 3 days/week) & 73.1 & 73.5 & 0.468 \\
\hline Fast food (> 3 days/week) & 19.9 & 23.7 & 0.724 \\
\hline French fries/potato chips (> 3 days/week) & 52.2 & 50.0 & 0.009 \\
\hline Cake/doughnuts/biscuits (> 3 days/week) & 46.1 & 40.1 & 0.139 \\
\hline Sweets/chocolates (> 3 days/week) & 64.1 & 57.4 & 0.022 \\
\hline Energy drinks (> 3 days/week) & 9.6 & 12.1 & 0.107 \\
\hline
\end{tabular}

self-reported and were therefore dependent upon the students' recall. The part of the questionnaire concerning dietary habits was qualitative and no portion sizes were evaluated. No total energy intake was measured, which may be a confounding factor. Furthermore, the present study was of a cross-sectional design and therefore the direction of causality cannot be assumed. Also, the SES was not assessed, since most of the students did not know their family's exact monthly income. However, the information provided by the present study adds to the limited existing data on lifestyle and dietary habits of Jordanian adolescents attending private and public schools.

\section{Conclusions}

A higher prevalence of overweight and obesity was found among students attending private schools as compared with students in public schools. The frequency of breakfast intake was significantly higher in private schools, whereas more frequent intakes of French fries and sweets were reported among adolescents attending public schools. Although the levels of physical activity were similar among students of both schools, females in general showed much lower physical activity compared with males. Promoting physical activity and health eating among Jordanian adolescents is recommended. Future research should examine the environmental and socioeconomic factors associated with obesity and lifestyle among adolescents in both types of schools.

\section{Implications of the study}

Physical inactivity and unhealthy dietary habits are known to be associated with body weight gain and poor health status of children and adolescents. In addition, studies have shown that children and adolescents who are physically active and consume healthy foods are less likely to be affected by type 2 diabetes, hypertension and abnormal lipid profile. The findings of the present study show that private as well as public schools need to pay more attention to adolescents' health behaviours. Our results highlight the need for educational programmes across the country to emphasize the importance of changing unhealthy behaviours and adopting healthy behaviours for life.

\section{Acknowledgements}

Funding: The authors would like to thank the Hashemite University for funding this research.

Competing interests: None declared.

\section{References}

1. Musaiger A. Food consumption patterns in Eastern Mediterranean Countries. Manama, Bahrain: Arab Center for Nutrition; 2011.

2. Musaiger AO, Al-Mannai M, Tayyem R, Al-Lalla O, Ali EY, Kalam F, et al. Prevalence of overweight and obesity among adolescents in seven Arab countries: a cross-cultural study. J Obes. 2012;2012:981390. 10.1155/2012/981390 PMID:23029605

3. Lobstein T, Baur L, Uauy R; IASO International Obesity TaskForce. Obesity in children and young people: a crisis in public health. Obes Rev. 2004 May;5 Suppl 1:4-104. PMID:15096099 
4. Al-Hazzaa HM, Abahussain NA, Al-Sobayel HI, Qahwaji DM, Musaiger AO. Lifestyle factors associated with overweight and obesity among Saudi adolescents. BMC Public Health. 2012;12:354. 10.1186/1471-2458-12-354 PMID:22591544

5. Musaiger AO, Bader Z, Al-Roomi K, D'Souza R. Dietary and lifestyle habits amongst adolescents in Bahrain. Food Nutr Res. 2011;55: 10.3402/fnr.v3455i3400.7122 PMID:21912533

6. Chakar H, Salameh PR. Adolescent obesity in Lebanese private schools. Eur J Public Health. 2006 Dec;16(6):648-51. PMID:16698887

7. Raja'a YA, Bin Mohanna MA. Overweight and obesity among schoolchildren in Sana'a City, Yemen. Ann Nutr Metab. 2005 Sep-Oct;49(5):342-5. PMID:16118485

8. Musaiger AO, Al-Hazzaa HM, Takruri HR, Mokhatar N Change in nutrition and lifestyle in the Eastern Mediterranean Region: health impact. J Nutr Metab. 2012;2012:436762. 10.1155/2012/436762

9. Qureshi F, Saqib A, Hussain J. Obesity prevalence among boys in public and private secondary schoolchildren. Prof Med J. 2011;18:489-93.

10. Al-Nuaim AA, Al-Nakeeb Y, Lyons M, Al-Hazzaa HM, Nevill A, Collins $P$, et al. The prevalence of physical activity and sedentary behaviours relative to obesity among adolescents from AlAhsa, Saudi Arabia: rural versus urban variations. J Nutr Metab. 2012; doi: 10.1155/2012/417589. PMID:22315673

11. Al-Hazzaa HM, Al-Sobayel HI, Musaiger AO. Convergent validity of the Arab Teens Lifestyle Study (ATLS) physical activity questionnaire. Int J Environ Res Public Health. 2011 Sep;8(9):3810-20. PMID:22016718

12. Cole TJ, Bellizzi MC, Flegal KM, Dietz WH. Establishing a standard definition for child overweight and obesity worldwide: international survey. BMJ. 2000 May 6;320(7244):1240-3. PMID:10797032

13. Al-Hazzaa HM, Al-Ahmadi M. A Self-reported questionnaire for the assessment of physical activity in youth $15-25$ years. Arab J Food Nutr. 2003;4(8):279-91.

14. Al-Hazzaa HM, Musaiger AO; ATLS Research Group. Arab Teens Lifestyle Study (ATLS): objectives, design, methodology and implications. Diabetes Metab Syndr Obes. 2011;4:417-26. PMID:22253540>

15. Al-Ahmadi M, Al-Hazzaa HM. Validity of a self-reported questionnaire for youth 15-25 years: comparison with accelerometer, pedometer and heart rate telemetry. Saudi Sports Med J. 2004;7:2-14.
16. Ainsworth BE, Haskell WL, Herrmann SD, Meckes N, Bassett DR Jr, Tudor-Locke C, et al. 2011 Compendium of physical activities: a second update of codes and MET values. Med Sci Sports Exerc. 2011 Aug;43(8):1575-81. PMID:21681120

17. Ridley K, Ainsworth BE, Olds TS. Development of a compendium of energy expenditures for youth. Int J Behav Nutr Phys Act. 2008;5:45. PMID:18782458

18. Bovet P, Chiolero A, Madeleine G, Paccaud F. Prevalence of overweight and underweight in public and private schools in the Seychelles. Int J Pediatr Obes. 2010 May 3;5(3):274-8. PMID:20184505

19. Szajewska H, Ruszczynski M. Systematic review demonstrating that breakfast consumption influences body weight outcomes in children and adolescents in Europe. Crit Rev Food Sci Nutr. 2010 Feb;50(2):113-9. PMID:20112153

20. Rampersaud GC, Pereira MA, Girard BL, Adams J, Metzl JD. Breakfast habits, nutritional status, body weight, and academic performance in children and adolescents. J Am Diet Assoc. 2005 May;105(5):743-60. PMID:15883552

21. Deshmukh-Taskar PR, Nicklas TA, O'Neil CE, Keast DR, Radcliffe JD, Cho S. The relationship of breakfast skipping and type of breakfast consumption with nutrient intake and weight status in children and adolescents: the National Health and Nutrition Examination Survey 1999-2006. J Am Diet Assoc. 2010 Jun;110(6):869-78. PMID:20497776

22. Verloigne $M$, Van Lippevelde $W$, Maes L, Yıldırım M, Chinapaw M, Manios Y, et al. Levels of physical activity and sedentary time among 10- to 12-year-old boys and girls across 5 European countries using accelerometers: an observational study within the ENERGY-project. Int J Behav Nutr Phys Act. 2012;9:34. PMID:22462550

23. Belcher BR, Berrigan D, Dodd KW, Emken BA, Chou CP Spruijt-Metz D. Physical activity in US youth: effect of race/ ethnicity, age, gender, and weight status. Med Sci Sports Exerc. 2010 Dec;42(12):2211-21. PMID:21084930

24. Private schools: who benefits? PISA in focus 2011/7. Paris, France: Organisation for Economic Co-operation and Development; 2011 (http://www.oecd.org/pisa/pisaproducts/ pisainfocus/48482894.pdf, accessed 27 March 2014).

25. Wenglinsky H. Are private high schools better academically than public high schools. Washington (DC): Center on Education Policy; 2007. 